\title{
A comparative study on the antioxidant and immunomodulatory properties of curcumin conjugated gold nanospheres and free curcumin
}

\author{
Leichombam Mohindro Singh ${ }^{1}$, Biswajit Chakraborty ${ }^{1}$, Ramkrishna $\mathrm{Pal}^{1}$, Anupam Nath $^{1}$, Sudip Pal ${ }^{2}$, \\ Dewan Shahidur Rahman ${ }^{2}$, Sujit Kumar Ghosh ${ }^{2}$, Mahuya Sengupta ${ }^{1 *}$ \\ ${ }^{1}$ Department of Biotechnology, ${ }^{2}$ Department of Chemistry, Assam University, Silchar, Assam, India.
}

\section{ARTICLE INFO \\ Article history: \\ Received on: 01/08/2017 \\ Accepted on: 26/09/2017 \\ Available online: 30/11/2017}

Key words:

Antioxidant; curcumin; oxidative stress; reactive oxygen species; reactive nitrogen species

\begin{abstract}
Curcumin, a phenolic compound isolated from the rhizomes of the plant Curcuma longa, has been known for decades. Owing to the fact of its hydrophobic nature and rapid metabolization, it has not been used as an effective drug so far. To solve the problem of bioavailability of curcumin, gold nanoparticles (cAuNps) reduced and stabilized with curcumin have been prepared. Afterwards, study for their antioxidant defenses and its effect on oxidative stress has been implemented. Cell cytotoxicity of both cAuNps $\left(2.91677 \times 10^{2}-2.91677 \times 10^{12}\right.$ particles $\left.\mathrm{ml}^{-1}\right)$ and free curcumin $(1 \mathrm{mM}-128 \mathrm{mM})$ were studied by 3-(4, 5-dimethylazol-2-yl)-2, 5-diphenyltetrazolium bromide) (MTT) assay. From the above studies, it was found that cAuNps could ameliorate the antioxidants defenses and could quench the ROS and RNS generated in the cells more significantly compared to free curcumin. This phenomenon is due to the abstraction of $\mathrm{H}$ atoms from phenolic functional groups of curcumin in the nanoconjugate form. Thus, the study proposes a strategy for increasing the bioavailability of curcumin as a therapeutic agent as well as increasing its activity due to the synergistic effect of gold conjugated to it.
\end{abstract}

\section{INTRODUCTION}

Curcumin or diferuloylmethane, chemically known as bis- $\alpha, \beta$-unsaturated $\beta$-diketone, is a potent natural remedy for many ailments since ancient times. It is isolated from the rhizome of Curcuma longa (turmeric), a traditional spice used in curry. It is the main component of turmeric exhibiting both keto and enol tautomerism (Figure 1) (Basu and Kumar 2014). During the past few decades, this agent has been extensively investigated for its pharmacological role that includes hepatoprotective and nephroprotective functions (Kiso et al., 1983; Venkatesan, 1998; Venkatesan et al., 2000). It has been shown that potent antiinflammatory as well as anti-cancer activities (Jurenka 2009; Salem et al., 2014). Several studies on the antimicrobial and

* Corresponding Author

Email: senguptamahuya35 @ gmail.com immunomodulatory activities of curcumin have been reported (Yadav et al., 2005; Moghadamtousi et al., 2014). An increasing number of studies show that polyphenolic nutritional are capable of blocking neuronal death in vitro and many therapeutic properties in animal models of neurodegenerative diseases including Alzheimer's (Hishikawa et al., 2012) and Parkinson's disease (Zbarsky et al., 2005; Mythri and Bharath, 2012). It has also been reported that curcumin possesses apoptotic activity against stomach and skin tumor (Azuine and Bhide 1992), breast cancer cells (Liu and Chen. 2013), and prostate cancer cells (Chen, 2015). A high correlation was found between curcumin-mediated apoptosis and intracellular ROS (Bhaumik et al., 1999). A recent study reported that curcumin inhibits proliferation of colon cancer cell lines (HT-29 and HCT-15) by arresting cells in G2-M phase (Hanif et al., 1997), down-regulates the expression of bcl-2 in tumor cells and induces apoptosis in NIH3T3 and leukemic cell line HL-60 (Jiang et al., 1996; Kuo et al., 1996). 
It has been reported to inhibit $\mathrm{H}_{2} \mathrm{O}_{2}$, tumor necrosis factor (TNF) and phorbol acetate induced NF- $\kappa$ B activation (Singh and Aggarwal 1995). Despite its significant therapeutic value, it has not yet been approved as a drug so far and its translation from basic research to clinical trials and human application is hindered due to its ready degradation and metabolization resulting in poor pharmacokinetics, low bioavailability, and pharmacological activity.

Curcumin's hydrophobic nature is one of the primary reasons for this poor water-solubility/suspension capacity (Anand et al., 2007). Till now a number of curcumin delivery strategies have been developed such as micelles (Ma et al., 2008), liposomal vesicles (Nguyen et al., 2016), nanoparticles (Bisht et al., 2007; Shaikh et al., 2009; Anand et al., 2010), nanoemulsions (Ganta and Amiji, 2009), phospholipid complexes (Maiti et al., 2007) and polymeric implants (Bansal et al., 2011) etc. to enhance its bioavailability.

Certain metal elements have also been studied extensively for localized drug delivery studies. Among these, nano formulations of gold $(\mathrm{Au})$ have been studied extensively as they are biologically non-reactive, supporting themselves as good candidates for in vivo analysis (Lewinski et al., 2008), with low cytotoxicity and tunable surface conformations due to localized surface plasmon resonance property (LSPR) (Jain 2009). Au nanoparticles possess easily controllable surface chemistry possessing versatility in adding surface functional groups (Delong et al., 2010) and ease in controlling particle shapes and sizes (Kim et al., 2009).

Before effective applications of nanoparticles as therapeutic agents, factors that are to be ensured is the prevention of their aggregation, increase in circulation time, the ability of targeting targets and their compatibility with blood. It has been reported that $\alpha, \beta$-unsaturated $\beta$-diketo moiety of curcumin makes an excellent chelating agent of metal ions including $\mathrm{Au}$ (Priyadarsini, 2014). Likewise, it has also been reported that compounds with structures containing at least two of the following functional groups: $-\mathrm{OH},-\mathrm{SH},-\mathrm{COOH},-\mathrm{PO}_{3} \mathrm{H}_{2}, \mathrm{C}=\mathrm{O},-\mathrm{NR}_{2},-\mathrm{S}-$ and $-\mathrm{O}-$ can give good chelation with metals (Lindsay 1996). As a result, certain ways of conjugation of curcumin and gold have been adopted. In one such approach, Manju and Sreenivasan have prepared curcumin conjugated gold nanoparticles using hyaluronic acid as reductant (Manju and Sreenivasan, 2012). In another approach, PVP (polyvinyl pyrrolidone) capped, trisodium citrate reduced curcumin conjugated gold nanoparticles have been prepared (Gangwar et al., 2012). The present study reports the single step synthesis of curcumin stabilized gold nanoparticles (cAuNps) where curcumin acts as both the reducing and stabilizing agent showing amelioration of antioxidant status and quenching of reactive oxygen species (ROS) and reactive nitrogen species (RNS) in macrophages (in vitro). Curcumin is able to reduce and stabilize gold is due to the fact that it can release $\mathrm{H}$ atoms (Sindhu et al., 2014). cAuNps so prepared has the advantage of improved solubility thereby increasing its bioavailability thus making it an attractive therapeutic agent.

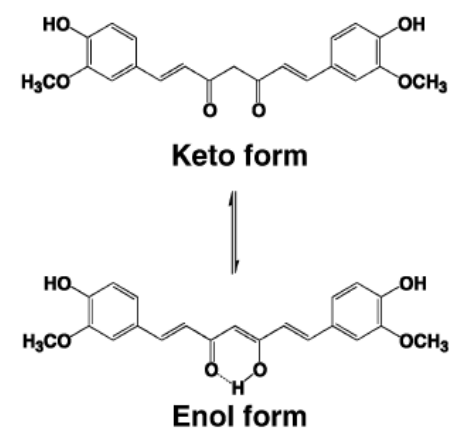

Fig. 1: keto and enol form of curumin.

\section{MATERIALS AND METHODS}

\section{Synthesis of curcumin stabilized gold nanospheres (cAuNps)}

cAuNps were prepared with a slight modification from $\mathrm{S}$. Manju and K. Sreenivasan. Here in this method, $20 \mathrm{ml}$ double distilled deionized water was taken; then added $500 \mu \mathrm{L}$ of $10 \mathrm{mM}$ gold solutions $\left(\mathrm{HAuCl}_{4} \cdot 2 \mathrm{H}_{2} \mathrm{O}\right)$ and $46 \mathrm{mg}$ curcumin. Then the whole solution was stirred for 5 minutes with continuous heating since curcumin is sparingly soluble in cold water. Then we added $100 \mu \mathrm{L}$ of sodium borohydride $\left(\mathrm{NaBH}_{4}\right)$ solution drop wise with continuous stirring for 30 minutes. Stirring of solution stopped when its color turns yellowish red, which indicated the formation of curcumin stabilized gold nanospheres. cAuNps so prepared were found to be stable at pH 7.2 (Singh et al., 2013).

\section{Characterization of curcumin stabilized gold nanospheres (cAuNps)}

Curcumin stabilized gold nanospheres (cAuNps) so prepared were characterized by UV-VIS spectrophotometer, transmission electron microscopy (TEM) and Fourier transform infrared spectroscopy (FTIR). Under normal condition, UV spectra of gold nanoparticles (AuNps) show their optimum peak at 520nm, which is the characteristic of AuNps. But after incorporation with curcumin, a phenolic compound, the peak of UV spectra has been shifted to $535 \mathrm{~nm}$ as a result of the red shifting of free AuNps. FTIR study of cAuNps was performed for a proper understanding of the conjugation pattern of free curcumin with AuNps. The mean particle diameter of cAuNps was measured by image-j software and was found to be $13 \mathrm{~nm}$ in size. Transmission electron micrograph (TEM) analysis of cAuNps was performed on a JOL, JSM-2100, JEOL-JAPAN and sample was prepared by placing a drop of the aqueous dispersion of cAuNps on the copper grid and allowing it to air dry. After storage for more than 3 months at room temperature, cAuNps, were found to be stable and it was confirmed by UV-VIS spectrophotometer.

\section{Animals}

Male Swiss albino mice (LACA strain) were purchased from the Pasteur Institute, Meghalaya, Shillong, India bearing license no. 34/DR/19666. Six to eight weeks old mice weighing around $20 \pm 1 \mathrm{~g}$ were preferred for all the experiments. All the experiments were done according to the guidelines of the 
Institutional Ethics Committee (IEC/AUS/2013-016). All animals were housed in polycarbonate cages at $22 \pm 1^{\circ} \mathrm{C}$ temperature with $85 \%$ relative humidity and 12 hours light-darkness room with standard food and water available ad libitum.

\section{Experimental design}

Thirty adult male Swiss albino mice of LACA strain weighing around $20 \pm 1 \mathrm{~g}$ were taken. Splenic macrophages were isolated and were randomly divided into three groups: control, curcumin-treated and cAuNps treated. Cell viability was analyzed by MTT assay followed by cell function assays like respiratory burst, SOD, the release of catalase and GSH to check the antioxidant status. The release of NO and MPO was done to analyze oxidative stress level.

\section{Isolation of splenic macrophages}

For the isolation of splenic macrophages, spleens were excised from the mice after they were sacrificed by cervical dislocation. They were then placed immediately in Alsever's solution and macerated properly in order to obtain a single cell suspension. Splenic macrophages were isolated (Chakraborty and Sengupta, 2012) and cell viability was determined by trypan blue dye exclusion technique. Nonspecific esterase staining was done for maintaining the specificity of cells. Finally, a concentration of $5 \times 10 \%$ cells population was obtained (Chakraborty and Sengupta, 2012).

\section{Cytotoxicity study}

The cytotoxicity study of curcumin stabilized gold nanoparticles (cAuNps) and curcumin was measured by MTT 3(4, 5-dimethylazol-2-yl)-2, 5-diphenyl-tetrazolium bromide) assay.

\section{MTT assay}

3-(4, 5-dimethylazol-2-yl)-2, 5-diphenyl-tetrazolium bromide (MTT) assay was performed in order to check the comparative cytotoxicity status of cAuNps and free curcumin. To perform this assay, two groups of cell aliquots with a concentration of $5 \times 10^{6} / \mathrm{ml}$ were taken. One group was treated with lipopolysaccharide (LPS) while the other group was kept untreated. These were kept overnight for $24 \mathrm{hrs}$ at $37^{\circ} \mathrm{C}$ in a $5 \%$ $\mathrm{CO}_{2}$ incubator. Cells were then treated for $1 \mathrm{hr}$ with different doses of cAuNps $\left(2.91677 \times 10^{2}-2.91677 \times 10^{12}\right.$ particles/ml $)$ and curcumin $(1 \mathrm{mM}-128 \mathrm{mM})$ respectively. Cytotoxicity was evaluated depending upon the enzymatic reduction of cells by MTT [3-(4, 5dimethylazol-2-yl)-2, 5-diphenyl-tetrazolium bromide) by using Jena Bioscience MTT cell viability assay kit (catalogue no.CPP$\mathrm{K} 03)$.

\section{Superoxide anion production assay}

This was performed to determine the amount of superoxide anions $\left(\mathrm{O}^{2-}\right)$ released inside phagocytic cells. The present assay was conducted based on the estimation of blue color formazan, which was formed by reduction of the yellow-colored nitroblue tetrazolium (NBT) by $\mathrm{O}_{2}$ ( ) (Sim et al., 2006).

\section{Nitric oxide release assay}

To determine the level of reactive nitrogen species (RNS), nitric oxide release assay was performed. For this purpose, cells of concentration $10^{6} \mathrm{ml}^{-1}$ were treated with curcumin and cAuNps separately and level of RNS released was estimated quantitatively after comparing with a sodium nitrate standard curve (Chakraborty and Sengupta, 2012).

\section{Myeloperoxidase (MPO) release assay}

In this assay, $100 \mu \mathrm{l}$ of cells suspension $\left(10^{6} / \mathrm{ml}\right)$ was taken in the three different groups of treatment. Cells were then stimulated with lipopolysaccharide or LPS $(100 \mathrm{ng} / \mathrm{ml})$ and incubated overnight at $37^{\circ} \mathrm{C}$ in a $5 \% \mathrm{CO}_{2}$ incubator. Cells were then centrifuged at $13000 \mathrm{rpm}$ for $10 \mathrm{mins}$ and the supernatant was kept at $-20^{\circ} \mathrm{C}$ for further analysis. Pellets which were obtained were then lysed with $0.1 \%$ SDS for 5 mins and centrifuged at 1300 rpm for 10 mins and the supernatant was collected for analysis of total MPO release.

A volume of $100 \mu \mathrm{l}$ from each of cell free supernatant and cell lysate were reacted with $500 \mu 1$ of substrate buffer orthophenylenediamine (OPD) and kept at $37^{\circ} \mathrm{C}$ for 20 mins. The reaction was stopped by adding $100 \mu \mathrm{l}$ of $2 \mathrm{~N}$ sulphuric acid $\left(\mathrm{H}_{2} \mathrm{SO}_{4}\right)$. The absorbance of samples was taken spectrophotometrically at 492nm (Bos et al., 1978).

\section{Superoxide dismutase (SOD) assay}

Superoxide dismutase assay (SOD) was performed to study the amount of inhibition of pyrogallol autoxidation by the enzyme. In short, cells of dilution $10^{6} / \mathrm{ml}$ from respective treatment groups were stimulated with LPS $(100 \mathrm{ng} / \mathrm{ml})$ and kept for overnight at $37^{\circ} \mathrm{C}$ in a $\mathrm{CO}_{2}$ incubator. Then a volume of $300 \mu \mathrm{l}$ of Tris-Hcl and 50 $\mu \mathrm{l}$ of EDTA was added to each microcentrifuge tube. A volume of $50 \mu \mathrm{l}$ of $(2.64 \mathrm{mM})$ of freshly prepared pyrogallol was added to each tube and absorbance was taken at $420 \mathrm{~nm}$ for 3 mins at an interval of 30 secs (Marklund and Marklund, 1974).

\section{Quantitation of non-protein bound thiol (GSH) and total protein thiols}

For quantification of non-protein bound thiol (GSH) and total protein thiols, cells of concentration $10^{6} \mathrm{ml}^{-1}$ were pelleted down by centrifuging at $800 \mathrm{rpm}$ for $5 \mathrm{mins}$. The same was afterward extracted in $0.5 \mathrm{ml} 5 \%$ TCA-10mM EDTA and kept on ice for 30 mins. The cell extracts were centrifuged at $3000 \mathrm{rpm}$ for 5 mins; supernatants were analyzed for total non-protein bound thiol whereas pellets were dissolved in 1\% SDS and analyzed for total protein bound thiol $(500 \mu \mathrm{l})$. Aliquots of supernatants of pellet suspension were mixed with reaction buffer $(0.5 \mathrm{M}$ Tris- $\mathrm{HCl}$, 8mM-EDTA, 2mM DTNB) and kept at $25^{\circ} \mathrm{C}$ in dark for $10 \mathrm{mins}$. Finally, absorbance was recorded at $412 \mathrm{~nm}$ (Baj et al., 2002). 


\section{Catalase assay}

This assay was performed to measure the rate of consumption of hydrogen peroxide $\left(\mathrm{H}_{2} \mathrm{O}_{2}\right)$ to water and oxygen by curcumin and cAuNps. For this, cells of concentration $10^{6} \mathrm{ml}^{-1}$ were taken and divided into their respective treatment groups. They were consequently lysed with sodium phosphate buffer containing Triton-X 100. Afterwards a reaction mixture containing $\left(\mathrm{H}_{2} \mathrm{O}_{2}, 50 \mathrm{mM}\right.$ Tris- $\left.\mathrm{HCl}, \mathrm{PH}-8.0\right) 20 \mu \mathrm{l}$ cell lysate making it to a final volume of $1 \mathrm{ml}$ was prepared. Then absorbance was taken at $240 \mathrm{~nm}$ in a spectrophotometer (Aebi, 1984).

\section{Statistical analysis}

For statistical analysis, Mann-Whitney $U$ test was performed in SPSS v16 to analyze the values of control, curcumin and cAuNps treated groups. The results are expressed as mean \pm standard error mean and all the experiments were done in triplicates.

\section{RESULTS}

\section{Synthesis and characterization of curcumin stabilized gold nanoparticles (cAuNps)}

Characterization of cAuNps was done by UV-Vis spectrophotometry, transmission electron microscopy (TEM) and Fourier transform infrared spectroscopy (FTIR). The shifting of surface plasmon resonance band of cAuNps at 535nm in the UVVis spectra Figure 2(C) from the standard plasmon resonance band of AuNps from 520nm which is known as red shift indicates the formation of particles in nano sizes. The ultra-morphological structure of cAuNps was determined by TEM. Figure 2(B) shows the uniform formation of cAuNps; morphologically, nanoparticles so prepared were found to be spherical in shape. The average size of cAuNps was calculated using image-j software and was found to be $13 \mathrm{~nm}$ in size. Figure $\mathbf{2 A}$ (I) and Figure $\mathbf{2 A}$ (II) gives the FTIR spectra of cAuNps and free curcumin respectively along with their important bands. Sivaraman et al., and Levchenko et al., have reported the role of ionization of $-\mathrm{OH}$ groups of the flavonoids; tannic acid and rutin in the formation of AuNPs (Sivaraman et al., 2010; Levchenko et al., 2011). Likewise, it is confirmed from the FTIR data of cAuNPs that $\mathrm{Au}^{3+}$ is being reduced as a result of enolic and phenolic - $\mathrm{OH}$ groups of curcumin. As evident from the Figure $2 \mathbf{A}(\mathbf{I})$, bands at $713 \mathrm{~cm}^{-1}$ and $1427 \mathrm{~cm}^{-1}$ corresponds to the olefinic in-plane bonding vibrations of the heptadiene chain of curcumin is observed in cAuNps (though broadening was observed with the vibrations at $1427 \mathrm{~cm}^{-1}$ ) which clearly indicates the presence of intact curcumin moiety in the cAuNps. The band around $1648 \mathrm{~cm}^{-1}$ associated with $\mathrm{C}-\mathrm{O}$ stretching of carboxylate anion on the surface of cAuNps (Manju and Sreenivasan, 2012). Similarly, the bands $1508 \mathrm{~cm}^{-1}$, $1029 \mathrm{~cm}^{-1}$ and $960 \mathrm{~cm}^{-1}$ that appear in cAuNps are due to vibrations of aliphatic $\mathrm{C}-\mathrm{H}$ stretches and mixed vibrations of $\mathrm{CH}_{3}$, aromatic $\mathrm{CCC}$ and $\mathrm{CCH}$ determining the action of curcumin as a capping agent (Yallapu et al., 2012). A broad band in the first spectra at about $3510 \mathrm{~cm}^{-1}$ is assigned to the $\mathrm{O}-\mathrm{H}$ stretching frequency which proves that curcumin particles successfully bind to AuNps (Sindhu et al., 2014).
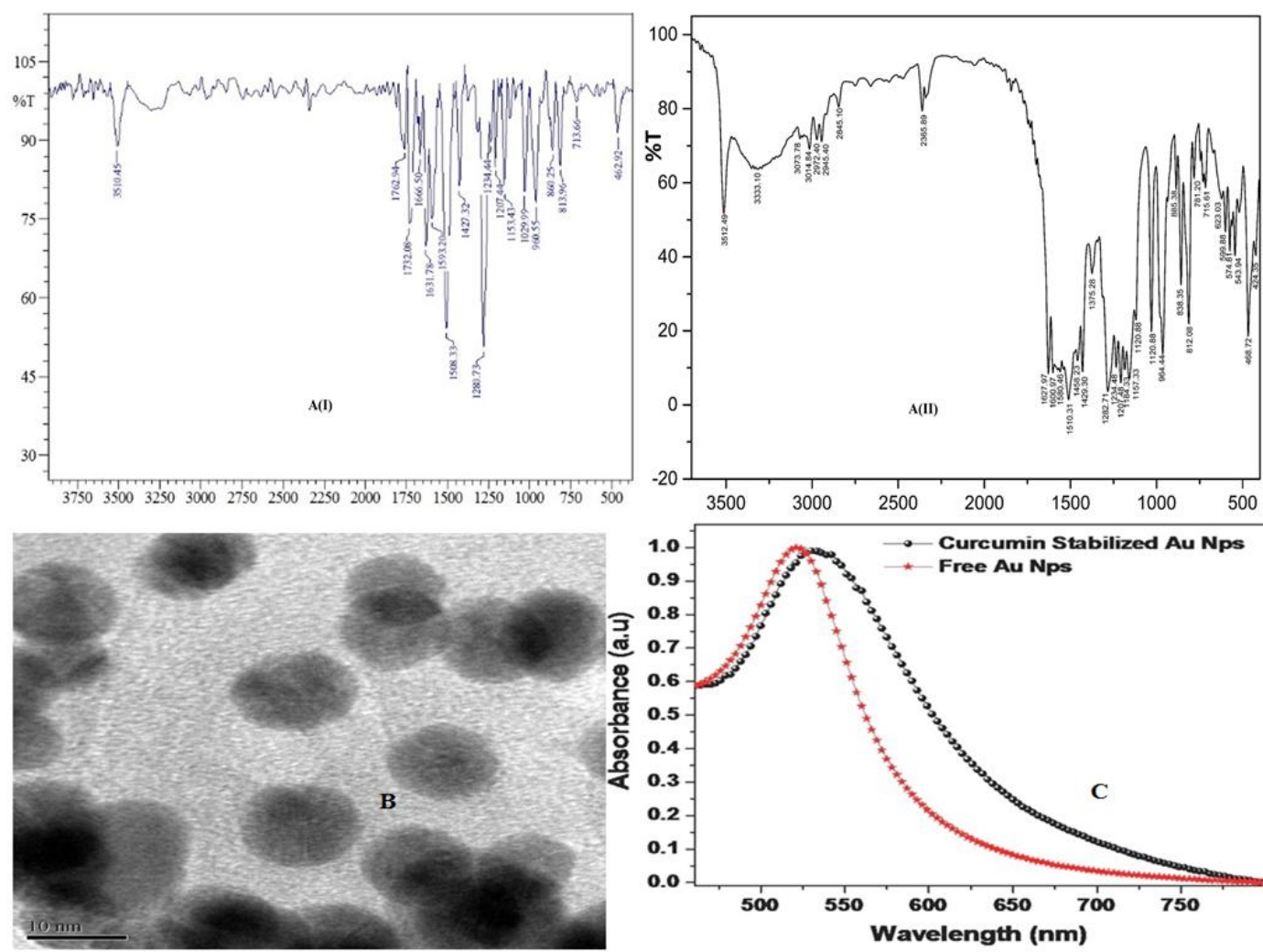

Fig. 2: Characterisation of cAuNPs: (A) FT-IR Spectra of (I) cAuNPs and (II) free curcumin (B) TEM image of cAuNPs (C) UV-VIS Spectra of cAuNPs. cAuNps; curcumin stabilized gold Nanoparticles, TEM; Transmission Electron Microscopy, FTIR; Fourier Transform Infrared Spectroscopy. 

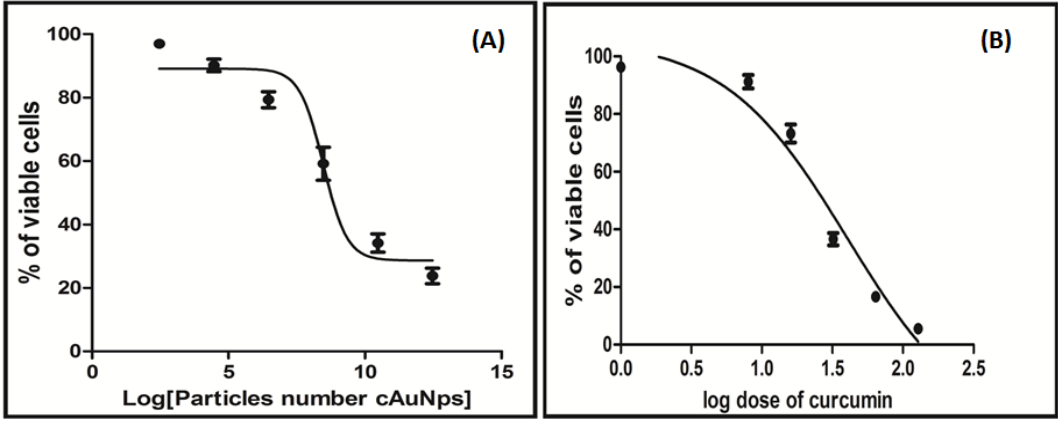

Fig. 3: Cytotoxicity study of (A) cAuNps and (B) free curcumin by MTT assay.
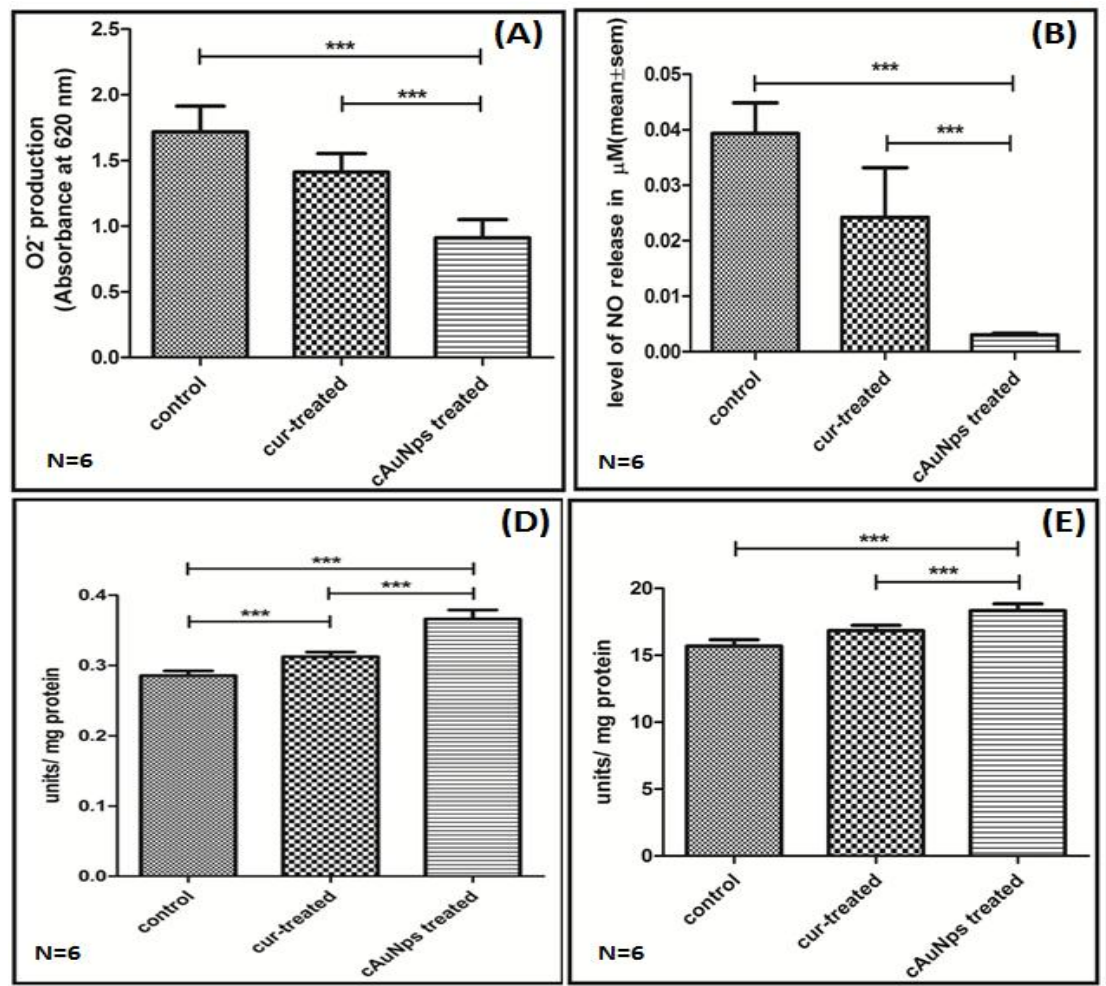
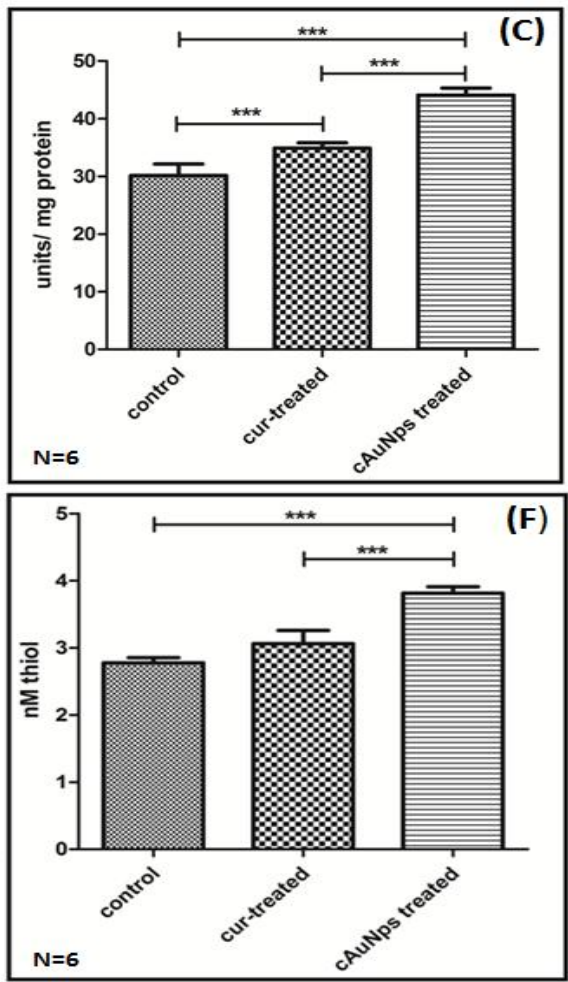

Fig. 4: Effect of curcumin and cAuNPs in vitro (A) Nitro blue tetrazolium assay $(p<0.001)$; (B) Nitric oxide release assay $(p<0.001)$; (C) Myeloperoxidase release assay ( $p<0.001)$; (D) Super oxide dismutase assay ( $p<0.001)$; (E) Catalase assay $(p<0.001)$; (F) Quantitation of non-protein bound thiol (GSH) and total protein thiols $(p<0.001)$. The data represented were in mean \pm S.E.M. $\mathrm{N}=$ no. of replica per observation.

\section{Cytotoxicity study of curcumin stabilized gold Nanoparticles (cAuNps) and free curcumin}

The cytotoxicity study of curcumin and cAuNps under in vitro condition was done in splenic macrophages isolated from Swiss albino mice (LACA strain) by MTT assay. After performing the non-regression analysis, it was obtained that the IC-50 for cAuNps and free curcumin were found to be $2.940 \times 10^{8}$ particles per $\mathrm{ml}$ and $7.825 \mathrm{mM}$ respectively (Figure $\mathbf{3 A}$ and Figure 3B).

\section{Nitro blue tetrazolium assay}

Nitro blue tetrazolium (NBT) assay was performed to assess the amount of superoxide anion $\mathrm{O}_{2}$ (') produced by transferring an electron from NADPH after treatment of macrophages with curcumin and cAuNps separately.
It was observed that when cells were treated with curcumin alone, the release of $\mathrm{O}_{2}\left(^{-}\right)$was not of significant compared to control $(1.717 \pm 0.196)$ with $p>0.05$. However, the $\mathrm{O}_{2}$ (c) level was decreased from $(1.412 \pm 0.14)$ to $(0.911 \pm 0.139)$ at $p<0.001$, after treating with cAuNps (Figure 4A).

\section{Nitric oxide release assay}

To determine the level of reactive nitrogen species (RNS), a family of antimicrobial molecules in splenic macrophages, nitric oxide release assay was performed. It was observed that there was a highly significant change in the level of RNS from $(0.039 \pm 0.006)$ to $(0.003 \pm 0.0003)$ with $p<0.001$ when cells were treated with cAuNps as compared with the RNS level of $(0.024 \pm 0.009)$ than that of control after treating with free curcumin (Figure 4B). 


\section{Myeloperoxidase release assay (MPO)}

In this assay, it was observed that the significant level of MPO increased to $(44.057 \pm 1.523)$ from $(34.887 \pm 0.948)$ with $p<0.001$ when treated with cAuNps compared to free curcumin (Figure 4C).

\section{Superoxide dismutase assay (SOD)}

The level of superoxide radical anions $\left(\mathrm{O}_{2}{ }^{-}\right)$was increased significantly from $(0.286 \pm 0.007)$ to $(0.366 \pm 0.013)$ with $p<0.001$ after the treatment of cAuNps. Similarly, when the same group of cells was treated with free curcumin $(0.313 \pm 0.006)$, there was a significant difference from that of control with $p<0.001$ (Figure 4D).

\section{Catalase assay}

In this assay, it was observed that the catalase release from cells treated with cAuNps increases significantly from $(15.689 \pm 0.483)$ to $(18.334 \pm 0.509)$ of control with $p<0.001$. However, for the curcumin treated group, such difference with that of control was not seen (Figure 4E).

\section{Quantitation of non-protein bound thiol (GSH) and total protein thiols}

It was observed that the amount of non-protein thiol and total protein thiols were increased significantly from $(2.776 \pm 0.076)$ to $(3.3810 .103)$ with $p<0.001$ after treatment of cAuNps compared to in the curcumin treated cells $3.06 \pm 0.039$ ) $(p<0.02)$ (Figure 4F).

\section{DISCUSSION}

Curcumin, an active agent of Curcuma longa, widely used in Ayurvedic medicine showed good effects against many ailments including cancer, sepsis, pain, and malaria (Aggarwal et al., 2007). Its potent antioxidant properties are because of its chemical structure which consists of two methoxylated phenols that are connected by $\alpha, \beta$ unsaturated carbonyl groups (Priyadarsini, 2014). It also possesses free-radical scavenging properties thereby playing an important role in the inhibition of carcinogenesis in their initial stages. Jovanovic et al., have reported that these free radicals scavenging properties of curcumin are due to its electron-transfer mechanism (Jovanovic et al., 1999). This strongly supports the candidacy of the same for dietary therapy of many ailments including cancer. However, as of now, in spite of such potential therapeutic properties, it has not been considered as a drug. Poor bioavailability and poor pharmacokinetics properties are considered the main factors for hindrance in calling curcumin a drug. Our previous studies have reported intrinsic antitumor property of gold nanoparticles targeting the tumor microenvironment through immune- effector cells (Pal et al., 2016). We thus tried to formulate a curcumin-gold nanocomposite to increase the bioavailability of curcumin and augment its anti-tumor activity by synergizing with gold NPs. Our first aim was to study the free radical scavenging properties of cAuNps (prepared using curcumin alone as the reducing and stabilizing agent of $\mathrm{Au}$ with free curcumin. Here, $\mathrm{Au}^{3+}$ ions are able to reduce by the virtue of their phenolic-OH and enolic-OH of curcumin. MTT assay was performed for both cAuNPs and free curcumin before carrying out the antioxidant and oxidative stress analyses. It was seen that the IC50 for cAuNPs and free curcumin were $2.40 \times 10^{8}$ particles per $\mathrm{ml}$ and $7.825 \mathrm{mM}$ respectively. It was found that the production of ROS and RNS in vitro, when treated with cAuNps, was significantly less in comparison to that of free curcumin treated group.

Certain reports have shown that curcumin can quench singlet oxygen and can inhibit the production of $\mathrm{H}_{2} \mathrm{O}_{2}$ in an aqueous environment (Phan et al., 2001; Das and Das, 2002). The ameliorated process of such antioxidant and free radical scavenging properties of cAuNps over free curcumin can be due to their interaction patterns of phenolic-OH and by abstraction of $\mathrm{H}$ atom from $\mathrm{C} 12$ methylene group of curcumin (Balasubramanyam et al., 2003; Hatcher et al., 2008). The main reason for this phenomenon might be attributed because of the increasing the availability of curcumin conjugated with the metal $\mathrm{Au}$, by which more $\mathrm{H}$ atoms are made available to cells.

ROS and RNS are being continuously produced because of normal body metabolism such as respiration and because of cell mediated immune functions. These may include free radicals such as superoxide anions radicals $\left(\mathrm{O}_{2}{ }^{-}\right)$, hydroxyl radicals $(\mathrm{OH})$ and non-free radicals such as hydrogen peroxide $\left(\mathrm{H}_{2} \mathrm{O}_{2}\right)$ and singlet oxygen $\left(\mathrm{O}^{-}\right)$species (Gulcin, 2006). They actually can cause damage to biomolecules including nucleic acids, proteins, and carbohydrates (Ding et al., 2005). If the levels of ROS and RNS are not optimized, they can lead to severe cellular dysfunction (Halliwell and Gutteridge, 1990). Antioxidant defenses mechanism plays an important role in checking the level of ROS and RNS in the living systems (Lai et al., 2001; Gulcin et al., 2002). Enzymatic antioxidants remove free radicals by converting various ROS and RNS into $\mathrm{H}_{2} \mathrm{O}_{2}$ and water while non-enzymatic antioxidants perform their defensives mechanisms by breaking free radical chain reactions (Shahidi and Zhong, 2010). In the respiratory burst assay, superoxide anions $\left(\mathrm{O}_{2}{ }^{-}\right)$, which are released by cells as a result of activation of NADPH oxidase with the uptake of oxygen, react with free hydrogen atoms from curcumin forming $\mathrm{H}_{2} \mathrm{O}_{2}$ and $\mathrm{H}_{2} \mathrm{O}$. The rate of formation of $\mathrm{H}_{2} \mathrm{O}_{2}$ and $\mathrm{H}_{2} \mathrm{O}$ is significantly lower when cells were treated with cAuNps than free curcumin.

It is very much important to analyze the activity of nitric oxide synthase enzymes to justify the level of RNS such as nitric oxide (NO) in cells. It was seen that the amount of RNS released by cells was significantly reduced when treated with cAuNps as compared to curcumin treatment. The enzyme myeloperoxidase (MPO) converts $\mathrm{H}_{2} \mathrm{O}_{2}$ to $\mathrm{HOCl}$ and $\mathrm{H}_{2} \mathrm{O}$ in contact with chloride ions $\left(\mathrm{Cl}^{-}\right)$which are found ubiquitously. It can be concluded from the results that when cells are being treated with cAuNps, $\mathrm{H}_{2} \mathrm{O}_{2}$ is being converted to its analogues more readily than curcumin.

Similarly, it has been reported that SOD, an antioxidant enzyme, plays an important role in quenching ROS (Imlay, 2013), thereby converting superoxide anions into $\mathrm{H}_{2} \mathrm{O}_{2}$ which are then 
converted to oxygen $\left(\mathrm{O}_{2}\right)$ and water $\left(\mathrm{H}_{2} \mathrm{O}\right)$ after being catalyzed by catalase enzymes. From the results, it can be concluded that the antioxidant defense properties of cAuNps are significantly higher as compared to curcumin as evident from both SOD and catalase assays. For further confirmation of the increased antioxidant status after cAuNp treatment, glutathione (GSH) level was analyzed. It can be attributed that GSH is the principal protective mechanism and a very important factor in the development of the immune response by effector immune cells (Townsend et al., 2003). It has also been reported that the scavenging oxygen radical by GSH is related to the repair and neutralization of ROS induced damage (Nimse and Pal, 2015). The increase in GSH content in this study after cAuNps treatment as compared with curcumin suggests that the former potentiates the cell survival system better than the latter.

\section{CONCLUSION}

cAuNps, which were prepared using curcumin alone as the reducing and stabilizing agent were found to ameliorate and quench the antioxidant defenses and pro-oxidant properties of cells. Due to conjugation pattern of curcumin and $\mathrm{Au}$ metals, the availability of $\mathrm{H}$-atoms to cells was increased which may be due to the donation of $\mathrm{H}$ atoms from phenolic groups. It is concluded that the increased free radical scavenging properties of cAuNps are due to the abstraction of hydrogen atoms from hydroxyl groups of curcumin. This phenomenon of increased antioxidant defenses and free radical scavenging properties of cAuNps might be a solution the problem of bioavailability of curcumin.

\section{ACKNOWLEDGEMENT}

We are thankful to the University Grant Commission (UGC) for providing Non-NET fellowship to Mr. Leichombam Mohindro Singh. We would also like to acknowledge the Sophisticated and Analytical Instrument Facility (SAIF), North Eastern Hill University for helping us in taking TEM images of cAuNps.

\section{REFERENCES}

121-126.

Aebi H. Catalase in vitro. Methods in enzymology. 1984; 105:

Aggarwal B B, Sundaram C, Malani N and Ichikawa H. Curcumin: the Indian solid gold. Adv Exp Med Biol. 2007; 595: 1-75.

Anand P, Kunnumakkara A B, Newman R A and Aggarwal B B. Bioavailability of curcumin: problems and promises. Mol Pharm. 2007; 4(6): 807-818.

Anand P, Nair H B, Sung B, Kunnumakkara A B, Yadav V R, Tekmal R R and Aggarwal B B. Design of curcumin-loaded PLGA nanoparticles formulation with enhanced cellular uptake, and increased bioactivity in vitro and superior bioavailability in vivo. Biochem Pharmacol. 2010; 79(3): 330-338.

Azuine $\mathrm{M}$ A and Bhide S V. Chemopreventive effect of turmeric against stomach and skin tumors induced by chemical carcinogens in Swiss mice. Nutr Cancer. 1992; 17(1): 77-83.

Baj G, Arnulfo A, Deaglio S, Mallone R, Vigone A, De Cesaris M G, Surico N, Malavasi F and Ferrero E. Arsenic trioxide and breast cancer: analysis of the apoptotic, differentiative and immunomodulatory effects. Breast Cancer Res Treat. 2002; 73(1): 61-73.
Balasubramanyam M, Koteswari A A, Kumar R S, Monickaraj S F, Maheswari J U and Mohan V. Curcumin-induced inhibition of cellular reactive oxygen species generation: novel therapeutic implications. J Biosci. 2003; 28(6): 715-721.

Bansal S S, Vadhanam M V and Gupta R C. Development and in vitro-in vivo evaluation of polymeric implants for continuous systemic delivery of curcumin. Pharm Res. 2011; 28(5): 1121-1130.

Basu A and Kumar G S. Interaction of the dietary pigment curcumin with hemoglobin: energetics of the complexation. Food Funct. 2014; 5(8): 1949-1955.

Bhaumik S, Anjum R, Rangaraj N, Pardhasaradhi B V and Khar A. Curcumin mediated apoptosis in AK-5 tumor cells involves the production of reactive oxygen intermediates. FEBS Lett. 1999; 456(2): 311-314.

Bisht S, Feldmann G, Soni S, Ravi R, Karikar C and Maitra A. Polymeric nanoparticle-encapsulated curcumin ("nanocurcumin"): a novel strategy for human cancer therapy. J Nanobiotechnology. 2007; 5: 3.

Bos A, Wever $\mathrm{R}$ and Roos D. Characterization and quantification of the peroxidase in human monocytes. Biochim Biophys Acta. 1978; 525(1): 37-44.

Chakraborty B and Sengupta M. Boosting of nonspecific host response by aromatic spices turmeric and ginger in immunocompromised mice. Cell Immunol. 2012; 280(1): 92-100.

Chakraborty B and Sengupta M. Supporting the immune system through functional modulation of carbon tetrachloride intoxicated splenic macrophages by administering Tinospora cordifolia. 2012 .

Chen Q H. Curcumin-based anti-prostate cancer agents. Anticancer Agents Med Chem. 2015; 15(2): 138-156.

Das K C and Das C K. Curcumin (diferuloylmethane), a singlet oxygen $((1) \mathrm{O}(2))$ quencher. Biochem Biophys Res Commun. 2002; 295(1): 62-66.

Delong R K, Reynolds C M, Malcolm Y, Schaeffer A, Severs T and Wanekaya A. Functionalized gold nanoparticles for the binding, stabilization, and delivery of therapeutic DNA, RNA, and other biological macromolecules. Nanotechnol Sci Appl. 2010; 3: 53-63.

Ding W, Hudson $\mathrm{L} \mathrm{G}$ and Liu $\mathrm{K}$ J. Inorganic arsenic compounds cause oxidative damage to DNA and protein by inducing ROS and RNS generation in human keratinocytes. Mol Cell Biochem. 2005; 279(1-2): 105-112.

Gangwar R K, Dhumale V A, Kumari D, Nakate U T, Gosavi S, Sharma R B, Kale S and Datar S. Conjugation of curcumin with PVP capped gold nanoparticles for improving bioavailability. Materials Science and Engineering: C. 2012; 32(8): 2659-2663.

Ganta S and Amiji M. Coadministration of Paclitaxel and curcumin in nanoemulsion formulations to overcome multidrug resistance in tumor cells. Mol Pharm. 2009; 6(3): 928-939.

Gulcin I. Antioxidant and antiradical activities of L-carnitine. Life Sci. 2006; 78(8): 803-811.

Gulcin I, Buyukokuroglu M E, Oktay M and Kufrevioglu O I. On the in vitro antioxidative properties of melatonin. Journal of Pineal Research. 2002; 33(3): 167-171.

Halliwell B and Gutteridge J M. Role of free radicals and catalytic metal ions in human disease: an overview. Methods Enzymol. 1990; 186: 1-85.

Hanif R, Qiao L, Shiff S J and Rigas B. Curcumin, a natural plant phenolic food additive, inhibits cell proliferation and induces cell cycle changes in colon adenocarcinoma cell lines by a prostaglandinindependent pathway. J Lab Clin Med. 1997; 130(6): 576-584.

Hatcher H, Planalp R, Cho J, Torti F M and Torti S V. Curcumin: from ancient medicine to current clinical trials. Cell Mol Life Sci. 2008; 65(11): 1631-1652.

Hishikawa N, Takahashi Y, Amakusa Y, Tanno Y, Tuji Y, Niwa H, Murakami N and Krishna U. Effects of turmeric on Alzheimer's disease with behavioral and psychological symptoms of dementia. AYU (An international quarterly journal of research in Ayurveda). 2012; 33(4): 499.

Imlay J A. The molecular mechanisms and physiological consequences of oxidative stress: lessons from a model bacterium. Nat 
Rev Microbiol. 2013; 11(7): 443-454.

Jain K K. The role of nanobiotechnology in drug discovery. Adv Exp Med Biol. 2009; 655: 37-43.

Jiang M C, Yang-Yen H F, Yen J J and Lin J K. Curcumin induces apoptosis in immortalized NIH $3 \mathrm{~T} 3$ and malignant cancer cell lines. Nutr Cancer. 1996; 26(1): 111-120.

Jovanovic S V, Steenken S, Boone C W and Simic M G. Hatom transfer is a preferred antioxidant mechanism of curcumin. Journal of the American Chemical Society. 1999; 121(41): 9677-9681.

Jurenka J S. Anti-inflammatory properties of curcumin, a major constituent of Curcuma longa: a review of preclinical and clinical research. Altern Med Rev. 2009; 14(2): 141-153.

Kim C K, Ghosh P and Rotello V M. Multimodal drug delivery using gold nanoparticles. Nanoscale. 2009; 1(1): 61-67.

Kiso Y, Suzuki Y, Watanabe N, Oshima Y and Hikino H. Antihepatotoxic principles of Curcuma longa rhizomes. Planta Med. 1983; 49(3): 185-187.

Kuo M L, Huang T S and Lin J K. Curcumin, an antioxidant and anti-tumor promoter, induces apoptosis in human leukemia cells. Biochim Biophys Acta. 1996; 1317(2): 95-100.

Lai L S, Chou S T and Chao W W. Studies on the antioxidative activities of Hsian-tsao (Mesona procumbens Hemsl) leaf gum. J Agric Food Chem. 2001; 49(2): 963-968.

Levchenko L, Golovanova S, Lariontseva N, Sadkov A, Voilov D, Shul'ga Y M, Nikitenko N and Shestakov A. Synthesis and study of gold nanoparticles stabilized by bioflavonoids. Russian Chemical Bulletin. 2011; 60(3): 426-433.

Lewinski N, Colvin V and Drezek R. Cytotoxicity of nanoparticles. Small. 2008; 4(1): 26-49.

Lindsay R. Food additives pp. 778-780. Food chemistry Fennema OR (ed). Marcel Dekker Inc., New York, NY, USA. 1996.

Liu D and Chen Z. The effect of curcumin on breast cancer cells. J Breast Cancer. 2013; 16(2): 133-137.

Ma Z, Haddadi A, Molavi O, Lavasanifar A, Lai R and Samuel J. Micelles of poly(ethylene oxide)-b-poly(epsilon-caprolactone) as vehicles for the solubilization, stabilization, and controlled delivery of curcumin. J Biomed Mater Res A. 2008; 86(2): 300-310.

Maiti K, Mukherjee K, Gantait A, Saha B P and Mukherjee P K. Curcumin-phospholipid complex: Preparation, therapeutic evaluation and pharmacokinetic study in rats. Int J Pharm. 2007; 330(1-2): 155-163.

Manju S and Sreenivasan K. Gold nanoparticles generated and stabilized by water soluble curcumin-polymer conjugate: blood compatibility evaluation and targeted drug delivery onto cancer cells. J Colloid Interface Sci. 2012; 368(1): 144-151.

Marklund S and Marklund G. Involvement of the superoxide anion radical in the autoxidation of pyrogallol and a convenient assay for superoxide dismutase. Eur J Biochem. 1974; 47(3): 469-474.

Moghadamtousi S Z, Kadir H A, Hassandarvish P, Tajik H, Abubakar S and Zandi K. A review on antibacterial, antiviral, and antifungal activity of curcumin. Biomed Res Int. 2014; 2014: 186864.

Mythri R B and Bharath M M. Curcumin: a potential neuroprotective agent in Parkinson's disease. Curr Pharm Des. 2012; 18(1): 91-99.

Nguyen T A, Tang Q D, Doan D C T and Dang M C. Micro and nano liposome vesicles containing curcumin for a drug delivery system. Advances in Natural Sciences: Nanoscience and Nanotechnology. 2016; 7(3): 035003

Nimse S B and Pal D. Free radicals, natural antioxidants, and their reaction mechanisms. Rsc Advances. 2015; 5(35): 27986-28006.

Pal R, Chakraborty B, Nath A, Singh L M, Ali M, Rahman D S, Ghosh S K, Basu A, Bhattacharya S, Baral R and Sengupta M. Noble metal nanoparticle-induced oxidative stress modulates tumor associated macrophages (TAMs) from an M2 to M1 phenotype: An in vitro approach. Int Immunopharmacol. 2016; 38: 332-341.

Phan T T, See P, Lee S T and Chan S Y. Protective effects of curcumin against oxidative damage on skin cells in vitro: its implication for wound healing. J Trauma. 2001; 51(5): 927-931.
Priyadarsini K I. The chemistry of curcumin: from extraction to therapeutic agent. Molecules. 2014; 19(12): 20091-20112.

Salem M, Rohani S and Gillies E R. Curcumin, a promising anti-cancer therapeutic: a review of its chemical properties, bioactivity and approaches to cancer cell delivery. Rsc Advances. 2014; 4(21): 1081510829.

Shahidi $\mathrm{F}$ and Zhong Y. Novel antioxidants in food quality preservation and health promotion. European Journal of Lipid Science and Technology. 2010; 112(9): 930-940.

Shaikh J, Ankola D D, Beniwal V, Singh D and Kumar M N. Nanoparticle encapsulation improves oral bioavailability of curcumin by at least 9-fold when compared to curcumin administered with piperine as absorption enhancer. Eur J Pharm Sci. 2009; 37(3-4): 223-230.

Sim Choi H, Woo Kim J, Cha Y N and Kim C. A quantitative nitroblue tetrazolium assay for determining intracellular superoxide anion production in phagocytic cells. Journal of Immunoassay and Immunochemistry. 2006; 27(1): 31-44.

Sindhu K, Rajaram A, Sreeram K and Rajaram R. Curcumin conjugated gold nanoparticle synthesis and its biocompatibility. Rsc Advances. 2014; 4(4): 1808-1818.

Singh D K, Jagannathan R, Khandelwal P, Abraham P M and Poddar P. In situ synthesis and surface functionalization of gold nanoparticles with curcumin and their antioxidant properties: an experimental and density functional theory investigation. Nanoscale. 2013; 5(5): 1882-1893.

Singh S and Aggarwal B B. Activation of transcription factor NF-kappa B is suppressed by curcumin (diferuloylmethane) [corrected]. J Biol Chem. 1995; 270(42): 24995-25000.

Sivaraman S K, Kumar S and Santhanam V. Room-temperature synthesis of gold nanoparticles - Size-control by slow addition. Gold Bulletin. 2010; 43(4): 275-286.

Townsend D M, Tew K D and Tapiero H. The importance of glutathione in human disease. Biomed Pharmacother. 2003; 57(3-4): 145 155.

Venkatesan N. Curcumin attenuation of acute adriamycin myocardial toxicity in rats. Br J Pharmacol. 1998; 124(3): 425-427.

Venkatesan N, Punithavathi D and Arumugam V. Curcumin prevents adriamycin nephrotoxicity in rats. Br J Pharmacol. 2000; 129(2): 231-234.

Yadav V S, Mishra K P, Singh D P, Mehrotra S and Singh V K. Immunomodulatory effects of curcumin. Immunopharmacol Immunotoxicol. 2005; 27(3): 485-497.

Yallapu M M, Othman S F, Curtis E T, Bauer N A, Chauhan N, Kumar D, Jaggi $\mathrm{M}$ and Chauhan S C. Curcumin-loaded magnetic nanoparticles for breast cancer therapeutics and imaging applications. International journal of nanomedicine. 2012; 7: 1761.

Zbarsky V, Datla K P, Parkar S, Rai D K, Aruoma O I and Dexter D T. Neuroprotective properties of the natural phenolic antioxidants curcumin and naringenin but not quercetin and fisetin in a 6OHDA model of Parkinson's disease. Free Radic Res. 2005; 39(10): 11191125 .

\section{How to cite this article:}

Singh LM, Chakraborty B, Pal R, Nath A, Pal S, Rahman DS, Ghosh SK, Sengupta M. A comparative study on the antioxidant and immunomodulatory properties of curcumin conjugated gold nanospheres and free curcumin. J App Pharm Sci, 2017; 7 (11): 056-063. 